\title{
Video Cartoons and Task-Induced Involvement: Effects to Pupils' L2 Incidental Literacy Acquisition
}

\author{
Elaiza Flor S. Arabiana ${ }^{\mathrm{a}, 1}$, Dayvin Adrian Ember A. Malifer ${ }^{\mathrm{b}, 2}$, Helen R. Betonio ${ }^{\mathrm{b}, 3^{*}}$ \\ ${ }^{a b c}$ English Department, MSU-Iligan Institute of Technology, Philippines \\ ${ }^{1}$ elaizaflor.arabiana@g.msuiit.edu.ph; ${ }^{2}$ dayvinadrianember.malifer@g.msuiit.edu.ph; ${ }^{3}$ helen.betonio@g.msuiit.edu.ph* \\ * corresponding author
}

ARTICLE INFO

\section{Article history}

Received 04 July, 2020

Revised 29 July, 2020

Accepted 3 September, 2020

Keywords

Incidental literacy acquisition task-induced involvement close-captioned videos

\begin{abstract}
While most studies that explored children's incidental literacy acquisition focused on input from written text, this quantitativequalitative study investigated the effects of using audio-visual input through close-captioned Aesop's Fables cartoons from PinkFong and Task-Induced Involvement ( $\mathrm{n}=6$ eight-year old pupils). Wilcoxon Signed Rank Test reveals that there is a significant difference in the pretest, immediate posttest and delayed posttests scores after the intervention as shown in the 90\%-95\% confidence level. This study also examines quantitatively the interconnectedness of the four areas of children's literacy skills: vocabulary, oral vocabulary and pronunciation, orthographic skill and comprehension after watching cartoons and engaging in tasks. Findings reveal a high correlation between the four literacy skills reflected as $95 \%$ confidence intervals. These findings reveal that incidental literacy acquisition is approached holistictically: the acquisition of one skill leads to the acquisition of the other literacy skills.
\end{abstract}

This is an open access article under the CC-BY-SA license.

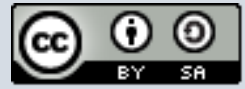

\section{Introduction}

The early years of a child's life provide avenues for language and literacy development (Mielonen \& Paterson, 2009). Years ago, children's exposure to language in their early years was only limited to their social interaction among their family members and other children. However, for many families now, "media has become a fabric of daily life" (Rideout, Hamel \& Kaiser Family Foundation, 2006, p.4). The digital age has created a huge impact in the children's routine and daily interactions (Vulchanova, Baggio, Cangelosi \& Smith, 2017). With the availability of new digital tools and media and them becoming commonplace, today's children have more opportunities to listen, hear and see language in different platforms and environments allowing them to develop emergent literacy skills through their exposure. These emergent literacy skills are listening, speaking, reading, and writing (Blanchard \& Moore, 2010).

The term "emergent" denotes the "developmental process of literacy acquisition and recognizes numerous forms of early literacy behavior" (Gunn, Simmons \& Kameenui, 2004, p.1). Zhao (2008) defines literacy as "the ability to interpret and understand messages relayed from others" (as cited in Mielonen and Paterson, 2009, p.15). It is a "fundamental skill that unlocks learning" (Terry, 2020) which is used as a tool for an individual to acquire knowledge independently. For children, language development and literacy start even before they enter primary school. This is referred as Emergent Literacy which refers to the information, capacity, and frame of mind that children develop as they start to learn reading and writing in the whole early childhood period (Save the Children, n.d.). 
Whitehurst and Lonigan (1998, p.1) refer to these skills and knowledge as "developmental precursors to reading and writing." The ubiquitous use of English in media has exposed children to the English language prior to the start of their formal L2 English learning which allowed them to receive rich syntactic and semantic input for language learning (De Wilde \& Eyckmans, 2017). The development of these emergent literacy skills continues as children explore the world filled with awe (Blanchard $\&$ Moore, 2010).

Emergent literacy as the first stage in reading development (Save the Children, n.d.) is also developed even when children are engaged in "non-intentional activities" especially with the use of media and technology. Hulstijn and Laufer (2001) define incidental learning as a "by-product of any activity not explicitly geared to lexical learning" (as cited in Zhao, et al., 2016). Blanchard and Moore (2010) use the term "non-intentional activities" referring to opportunities in which children are exposed to language and pictures but the exposure does not have an intended learning objective or curriculum. Young children may simply be watching, listening, and talking to others who are sharing the digital media experience. This digital experience can be considered play, but learning is achieved in this phenomenon without them even noticing it happening. Huckin and Coady $(1999$, p.18) define this incidental language acquisition as a "by-product, not the target, of the main cognitive activity" (as cited in De Wilde \& Eyckmans, 2017). Saracho and Spodek (2006) explain that reading and writing skills are developed even when the learner is playing (as cited in Mielonen and Paterson, 2009). In second language acquisition, input plays a major role which makes audio-visual input, the video, a good source of L2 input (Perez \& Rodgers, 2019).

As early as the late 1970s, research on the impact of the mass media on language development began (Vulchanova, Baggio, Cangelosi \& Smith, 2017). One of the few earliest studies that dealt with audio-visual input among young learners was conducted by Winn (1977 as cited in Vulchanova, Baggio, Cangelosi \& Smith, 2017) which utilized the effect of the children's television programme Sesame Street on language development. The findings reveal that it has significant effects, however, only in combination with adult intervention. d'Ydewalle and Van de Poel (1999) in Denmark utilized subtitled television programs in a foreign language as language input to Dutch speaking children. They found that children tend to acquire more when the foreign language is in the sound form than in the written form (subtitles). In the following years, the dearth of studies that explored the effects of digital media on emergent literacy skills development emanate from television and computer studies (Blanchard \& Moore, 2010).

Recently, studies that explored incidental literacy among young learners include Jensen (2016) which explored Extramural English activities that include gaming, watching television and listening to music in relation to vocabulary learning. Language input and the child's interaction with the environment play a significant role in language development as highlighted in the language acquisition theories (Vulchanova, Baggio, Cangelosi \& Smith, 2017). As such, this study aims to determine whether the integration of digital media (audio-visual input), particularly animated cartoons with closed captions (CC) as language input and Task-Induced Involvement (TII) as child's interaction with the environment will lead to the pupils' L2 Incidental Literacy Skills Acquisition (ILSA). With this new digital reality, the study intends to explore its effect on the children's acquisition of the basic human skill: language. Harun and Tedlos (2013) found that children have the tendency to take cartoons as their models and to reflect the characters in their daily games through the imitation of a few lines uttered or the behaviors acted by the cartoon characters they associate themselves with. Children who experience and are exposed to media-digital input such as animated cartoons may lead to more opportunities to incidentally learn more language items. De Wilde \& Eyckmans (2017) findings confirm that language is incidentally acquired by children before the start of formal English instruction through the exposure they receive from media, specifically, gaming and computer use which showed a significant relationship to the children's test results.

The dearth of studies mentioned prove that few studies deal with younger language learners' incidental literacy skills acquisition since most studies dealt with older participants (teenagers and university students). These studies on adult learners also addressed learner's incidental literacy input usually through reading from written texts and which focused only on gains obtained from one skill especially vocabulary (Zhao, et al., 2016; Ponniah, 2011). This is not surprising since vocabulary is the most significant component of L2 knowledge for all learners to develop whether the learner aims for academic or interpersonal competence (Savielle-Troike, 2012). These studies include vocabulary 
gains from reading and listening (Xiaoning \& Feng, 2017), L2 listening using a dimensions framework (Zeeland \& Schmitt, 2013) and reading and translation (Huang, 2008). Previous research on audio-visual input still focused on older learners only (Lin, 2010), gaming and learning L2 vocabulary (Sylven \& Sundqvist, 2012), and gaming frequency and game type as predictors of L2 vocabulary learning (Sundqvist, 2019).

Integrating Task-Induced Involvement (TII) after the audio-visual input, this study investigates the processes of the children's incidental acquisition of new words or lexical items (vocabulary), understanding how these words are put together and understanding the plot of a story (comprehension), acquiring the ability to write and spell the words they have seen and heard onscreen (orthography) and acquiring the ability to pronounce new words or lexical items by imitating the sound from the video (pronunciation) after multiple exposure to two video cartoons. This process is operationally defined in this study as Incidental Literacy Skills Acquisition (ISLA), the phenomenon in which learners unintentionally learn new literacy skills: vocabulary skill, pronunciation, orthography skill and comprehension skill. This study aims to answer the following research questions: (1). What is the level of literacy skills of the students before the intervention? (2). Is there a significant effect on the children's literacy skills before and after the intervention? (3). What is the extent of the learners' incidental literacy skills acquisition?

The null hypothesis (H0) is that there is no significant effect in the student's incidental vocabulary acquisition after the intervention of animated cartoons with closed-captions with the facilitation of Task-Induced Involvement where the extent of comprehension does not lead to the incidental acquisition of vocabulary, pronunciation, comprehension and orthographic skill. While the alternative hypothesis (H1) is that there is a significant effect in the student's incidental vocabulary acquisition after the intervention of animated cartoons with closed-captions with the facilitation of Task-Induced Involvement where the extent of comprehension leads to the incidental acquisition of vocabulary, pronunciation, comprehension and orthographic skill.

In this study, the process of Incidental Literacy Skills Acquisition is explored anchoring on Dual Coding Theory by Paivio (2006) and Involvement Load Hypothesis developed by Laufer and Hulstijn (2001). Anchored on the Dual Coding Theory (DCT) by Paivio (2006), this study examines how the verbal, nonverbal and textual cues affect the learners' SLA in terms of comprehension, vocabulary, orthography, and pronunciation. The DCT has been directly used in literacy and language learning as a general cognition theory (Kanellopoulou, Kermanidis and Kanellopoulou, 2019). According to Paivio (2006), the Dual Coding Theory involves the two distinct subsystems activity - the verbal and the nonverbal system. The verbal system specializes in dealing with language (text, sound, or sign language) and the nonverbal specializes in dealing with non-linguistic objects (symbols, pictures, or videos) (Paivio, 2014 as cited in Kanellopoulou, Kermanidis and Giannakoulopoulos 2019). Paivio (2006) further adds that these two systems are composed of internal representational units, which he calls logogens and imagens, which are both activated when one recognizes, manipulates, or thinks of words and things. Hence, these units can function unconsciously to improve cognitive performance (Paivio, 2014 as cited in Kanellopoulou, Kermanidis and Giannakoulopoulos, 2019). The representations of these units are modality-specific (Paivio, 2006) so every visual, auditory, haptic or feel and motor properties of language that one encounters correspond to a different logogen and imagen. These representation units are connected to a sensory input and response output systems as well as to each other so that they can function independently or cooperatively to mediate nonverbal and verbal behavior (Paivio, 2006). In simpler terms, this theory proposes that both the verbal and nonverbal systems are involved in the learners' language phenomena. The children's exposure to animated digital media, which comprises verbal and nonverbal cues, makes this theory relevant to this study.

Language learning as a process in which verbal and image representations are absorbed by the brain is a complex process. When the learners already acquired language items comprehensible and appropriate for their level from the video materials, their ability to remember and recall what they have learned - immediate or after a span of time- becomes the next concern. Thus, this paper also probes at the learners' retention of information anchoring on the Depth of Processing (DOP) model by Craik and Lockhart (1972) which states that there are three forms that a learner deals with information. The first form is structural processing which refers to encoding the appearance of something that resembles typescript of the word (orthographic skill when acquired and imitated). 
This is also referred to as formative processing which is at shallow level (Liu, 2015). The second form is phonemic processing which associates the sound (pronunciation skill when acquired and imitated). These two forms are both 'shallow processing'. The last form is semantic processing which happens when learners encode and analyze the meaning of a word and then relate it to similar words with similar meaning (vocabulary skill and comprehension skill) (Liu, 2015). This study focuses on both 'shallow' and 'deep processing' of the lexical items mediated through digital media which involve meaningful and complex analyses (sound, text, image, thinking, association) of information that would lead to longer retention time and enhance easy access from memory (Liu, 2015).

In the present study, DOP is associated with Incidental Literacy Skills Acquisition, in which structural, phonemic, and semantic elements are integrated into one medium. This study takes on a material that can put these elements together into test with cartoon videos containing captions embedded on them. This multimedia material contains text, sound and image that would further motivate and facilitate the acquisition of the mentioned literacy skills and then guarantee retained knowledge. In relation to DOP, a study by Hulstijn \& Laufer (2001) identified the components of incidental tasks which are conducive to the kind of elaborate processing and measurement of the DOP. They proposed the task-specific construct and named it as Task-induced Involvement (TII) for L2 vocabulary acquisition. The fundamental idea of this hypothesis named as Involvement Load Hypothesis is that the acquisition of new words and retention of unfamiliar words are affected by the amount and gravity of involvement in processing these new words. Involvement Load has three components: need, search and evaluation (Liu, 2015).

Following the principles cemented by the theories in the study's framework, the research proposes that children who repeatedly watch videos with verbal, visual, and textual cues which they never encountered before, and who participate in the integration of activities in the TII will incidentally acquire L2 literacy skills. These audio-visual-textual cues from the videos viewed by the learners all represent the conceptual meaning of the word absorbed during the cognitive processes of the viewers. These cues are arranged and integrated in the memory through the activation of and interaction between visual and verbal cognitive processing. The audio cues are aimed to induce the learners' pronunciation skills. The visual cues together with the audio and textual cues are aimed to induce the learners' vocabulary, orthography, and comprehension skills, thus their L2 Incidental Literacy Skills Acquisition. Task-induced Involvement facilitates the comprehension, new vocabulary and concept absorption after the viewing experience which leads to knowledge processing, hence the Incidental Literacy Skills Acquisition.

Producing competent readers and writers in the later stage of their life is achieved when there is a support for children's language and literacy development (Timothy \& Christopher, 2017). As such, there is a need to enrich the literature conducted among young learners or children's incidental literacy skills development through audio-visual input. There is also a lack of empirical research that investigated the interconnectedness or the holistic process of incidental language acquisition of comprehension, vocabulary, pronunciation and orthographic skills. Furthermore, no recent study has further utilized both audio-visual input and task-induced involvement as tools in incidental literacy skills acquisition. These are the gaps that the current study aims to address.

\section{Method}

The study is a quantitative-qualitative pre-experimental research design (single group) which did not employ a comparison group. This study used a pretest, a one-time immediate posttest and a onetime delayed posttest method to determine the effects of video materials with closed-captions and the task-induced involvement (TII) in the pupils' literacy skills acquisition. The design of this study compared the change in the subjects' literacy skills scores before and after the experimental intervention. The qualitative aspect of the study is the assessment of the incidental acquisition of the comprehension skills of the respondents through the TII.

The study was conducted at a Public Elementary School in the Southern part of the Philippines. Owing to the school's locality which is a 30-minute motorcycle ride to the city area, the residents have limited access to media found in the internet and cable TV which is of primary importance considered in this study. The class distribution of its pupils was also considered where the classes are heterogenous, and the pupils are not sectioned according to their ranks. 
Participants were selected based on a given set of criteria. All participants must be 8 years of age, a current Grade 2 pupil of the research locale, have no exposure to English language cable television and internet at home, be a Sebuano native speaker, uses his or her native tongue in speaking outside the school and at home, interested and willing in participating, and must not have watched Pinkfong Aesop Fables videos before. Also, a very important criterion is the children should be in the Instructional level based on their Philippine Informal Reading Test result. To ensure that the pupils have the same literacy skills level, those who passed the given criteria were also subjected to a short standardized reading test, spelling and comprehension test. Only six pupils passed the criteria given and the tests conducted. These pupils also had no prior knowledge about the methodology and the video materials.

Research instruments utilized for the intervention were two Aesop Fables videos from PinkFong's YouTube channel, "The Lion and the Mouse" and "The Greedy Dog." These videos were also validated to be free from violent scenes and appropriate for the Grade 2 level by a Developmental Psychology professor and her Developmental Psychology class. The length of the videos was less than 3 minutes which was a primary consideration in determining the 10-minute attention span of eight-year old children (Kapur, 2011). There were also 16 target words for each video. Furthermore, the validated tasks for the task-induced involvement integrated in this study were classified as basic, moderate, and advanced based on Hulstijn and Laufer (2001). These were given to the participants collectively every after the audio-visual input as fun activities and were nor graded at all. These also used various colorful activity materials such as flash cards and poker chips. The tasks allowed the children to discuss and deliberate answers as a group. Table 1 below presents the summary of the data gathering procedure which was applied to both Videos 1 and 2.

Table 1. Summary of Data Gathering Procedure

\begin{tabular}{|c|c|}
\hline Data Gathering Stages & Research Instrument \\
\hline Day 0 & $\begin{array}{c}\text { Pilot Testing } \\
\text { Audio-Visual Assessment Tool through Powerpoint }\end{array}$ \\
\hline Day 1 Pre-test & \\
\hline $\begin{array}{l}\text { Day } 2 \text { (Video 1) } \\
\text { First Video Exposure }\end{array}$ & Video 1 and Tasks in Basic Category \\
\hline $\begin{array}{l}\text { Day } 3 \text { (Video 1) } \\
\text { Second Video Exposure }\end{array}$ & Video 1 and Tasks in Moderate Category \\
\hline $\begin{array}{l}\text { Day } 4 \text { (Video 1) } \\
\text { Third Video Exposure }\end{array}$ & Video 1 and Tasks in Advanced Category \\
\hline $\begin{array}{l}\text { Day } 5 \text { Immediate Posttest } \\
4 \text { days after the last video exposure and } 8 \text { days after the } \\
\text { pretest: Delayed Posttest }\end{array}$ & Audio-Visual Assessment Tool through Powerpoint \\
\hline
\end{tabular}

The scores were recorded and compared across all skills and per accumulated score from the pretest, immediate posttest and posttest. Furthermore, the scores were statistically analyzed via nonparametric analog t-tests for paired data sets: Wilcoxon Signed Rank Test. This test was used to determine if there are significant differences between the pupils' pretest scores vs. immediate posttest scores, immediate posttest scores vs. delayed posttest scores, and pretest scores vs. delayed posttest scores before and after the intervention. Due to the small sample size, Kendall Rank Order Correlation Test is the ideal test (De Wilde \& Eyckmans, 2017) which was used to determine the significant interrelationships between the scores. The qualitative analysis was also applied to the observational data obtained from the pupils' performances in the tasks.

\section{Results and Discussion}

\subsection{Significant Effect After the Intervention}

This study found that multiple exposures to English animated video cartoons with closed captions (CC) and Task-Induced Involvement can lead to the incidental literacy acquisitions of vocabulary, pronunciation and orthographic skills which also facilitate comprehension skills of children language learners. Test scores for each video exposure are presented separately in this section: Video 1 and 
Video 2. The succeeding tables present a comparison of the scores obtained by the pupils in the pretest, immediate posttest, and delayed posttest. It is important to note that the increase of test scores is compared in this manner: pretest and immediate posttest; immediate posttest and delayed posttest; and pretest and delayed posttest scores in the three literacy skills.

Table 2 presents the scores of the pupils after their exposure to Video 1 . The figures alone show that there are score differences as shown in the significant increase in particular to the pretest versus immediate posttest scores and changes in the immediate posttest versus posttest scores across the three skills. This supports the claim that there are literacy skills acquisitions after the intervention.

Table 2. Score Comparisons of Pretest, Immediate Posttest and Posttest for Video 1

\begin{tabular}{|c|c|c|c|c|c|c|c|c|c|c|c|c|}
\hline \multirow[t]{2}{*}{ Pupils } & \multicolumn{3}{|c|}{ Vocabulary } & \multicolumn{3}{|c|}{ Pronunciation } & \multicolumn{3}{|c|}{ Orthography } & \multicolumn{3}{|c|}{ Accumulated } \\
\hline & Pre & $I P$ & $P$ & Pre & $I P$ & $P$ & Pre & $I P$ & $P$ & Pre & $I P$ & $P$ \\
\hline A & 0 & 6 & & 0 & 5 & & 0 & 4 & i & 0 & 15 & 14 \\
\hline B & 2 & 10 & & 1 & 9 & & 1 & 5 & i & 4 & 24 & 21 \\
\hline $\mathrm{C}$ & 1 & 4 & & 1 & 3 & & 0 & 2 & i & 2 & 9 & 15 \\
\hline $\mathrm{D}$ & 0 & 4 & & 0 & 3 & & 0 & 1 & & 0 & 8 & 6 \\
\hline $\mathrm{E}$ & 0 & 0 & & 0 & 0 & & 0 & 0 & & 0 & 0 & 5 \\
\hline $\mathrm{F}$ & 0 & 9 & & 0 & 8 & & 0 & 6 & i & 0 & 23 & 22 \\
\hline
\end{tabular}

IP - Immediate Posttest P- Posttest

Table 3 presents the statistical presentation of the summary of the significant differences between the pretest and immediate posttest, immediate posttest and delayed posttest, and pretest and delayed posttest scores in the three literacy skills. As presented in the table, the immediate posttest and the delayed posttest scores in the pronunciation and orthographic skill have no significant differences which means that the scores in the immediate posttest were mostly retained in the delayed posttest. This is similar for the accumulated immediate posttest and posttest score.

Table 3. Table of Significant Differences of Scores for Video 1 as Tested via Wilcoxon Signed Rank Test (nonparametric analog of the t-test for paired data sets)

\begin{tabular}{|c|c|c|c|c|c|c|c|c|}
\hline Variable & $\begin{array}{l}\text { Imm } \\
\text { Vocab }\end{array}$ & $\begin{array}{l}\text { Post } \\
\text { Vocab }\end{array}$ & $\begin{array}{l}\text { Imm } \\
\text { Pron }\end{array}$ & $\begin{array}{l}\text { Post } \\
\text { Pron }\end{array}$ & $\begin{array}{l}\text { Imm } \\
\text { Ortho }\end{array}$ & $\begin{array}{l}\text { Post } \\
\text { Ortho }\end{array}$ & $\begin{array}{l}\text { Imm } \\
\text { Total }\end{array}$ & $\begin{array}{l}\text { Post } \\
\text { Total }\end{array}$ \\
\hline \multicolumn{9}{|l|}{ Pre Vocab } \\
\hline \multicolumn{9}{|l|}{ Imm Vocab } \\
\hline \multicolumn{9}{|l|}{ Pre Pron } \\
\hline \multicolumn{9}{|l|}{ Imm Pron } \\
\hline \multicolumn{9}{|l|}{ Pre Ortho } \\
\hline \multicolumn{9}{|l|}{ Imm Ortho } \\
\hline \multicolumn{9}{|l|}{ Pre Total } \\
\hline \multicolumn{9}{|l|}{ Imm Total } \\
\hline gend:Perce & of Confi & e Leve & & $5 \%$ & & & & \\
\hline
\end{tabular}

Table 4 presents the pretest, immediate posttest, posttest scores for each literacy skill and the accumulated scores of the vocabulary, orthographic and pronunciation literacy skills tests for Video 2. It clearly presents the increase of the scores from pretest to immediate posttest, the increase of the scores from pretest to posttest and consistent scores from immediate posttest to the posttest. As shown, the scores of the participants have increased and there are acquisitions in the vocabulary, pronunciation, and orthographic skills on the target words in Video 2, and some of these acquisitions were retained by the children after four days. The immediate posttest-posttest scores of pupils A and $\mathrm{C}$ were maintained. 
Table 4. Score Comparisons of Pretest, Immediate Posttest and Posttest for Video 2

\begin{tabular}{cccccccccccccc}
\hline Pupils & \multicolumn{3}{c}{ Vocabulary } & \multicolumn{2}{c}{ Pronunciation } & \multicolumn{3}{c}{ Orthography } & \multicolumn{3}{c}{ Accumulated } \\
\hline & Pre & IP & P & Pre & IP & P & Pre & IP & P & Pre & IP & P \\
\hline A & 1 & 6 & 6 & 0 & 5 & 5 & 1 & 4 & 4 & 2 & 15 & 15 \\
B & 2 & 11 & 9 & 0 & 9 & 7 & 1 & 8 & 6 & 3 & 28 & 22 \\
C & 1 & 5 & 5 & 0 & 5 & 5 & 0 & 4 & 4 & 1 & 14 & 14 \\
D & 1 & 3 & 3 & 0 & 2 & 1 & 0 & 1 & 0 & 1 & 6 & 4 \\
E & 2 & 2 & 2 & 0 & 2 & 1 & 0 & 1 & 1 & 2 & 5 & 4 \\
F & 1 & 5 & 5 & 0 & 2 & 3 & 0 & 2 & 2 & 1 & 9 & 10 \\
\hline IP - Immediate Posttest P-Posttest & & & & & & & & &
\end{tabular}

Table 5 presents the statistical presentation using the Wilcoxon Signed Rank Test of the pretest vs. immediate posttest, immediate posttest vs. posttest and pretest vs. posttest scores in Video 2 which compares all of the test scores across all the three literacy skills to determine if the differences in the scores are significant.

The results show that there is a significant difference in the literacy skills' pretest vs. immediate posttest and pretest vs. posttest score comparisons with 90\%-95\% confidence levels. This indicates that the pretest-immediate posttest and pretest-posttest score differences are significant, thus, the increase in the test scores from the pretest to the immediate posttest and to the posttest as shown in Table 3 is significant.

Table 5. Table of Significant Differences for Video 2 as Tested Via Wilcoxon Signed Rank Test (nonparametric analog of the t-test for paired data sets)

\begin{tabular}{|c|c|c|c|c|c|c|c|c|}
\hline Variable & $\begin{array}{l}\text { Imm } \\
\text { Vocab }\end{array}$ & $\begin{array}{c}\text { Post } \\
\text { Vocab }\end{array}$ & $\begin{array}{l}\text { Imm } \\
\text { Pron }\end{array}$ & Post Pron & $\begin{array}{l}\text { Imm } \\
\text { Ortho }\end{array}$ & $\begin{array}{l}\text { Post } \\
\text { Ortho }\end{array}$ & $\begin{array}{l}\text { Imm } \\
\text { Total }\end{array}$ & $\begin{array}{l}\text { Post } \\
\text { Total }\end{array}$ \\
\hline \multicolumn{9}{|l|}{ Pre Vocab } \\
\hline \multicolumn{9}{|l|}{ Imm Vocab } \\
\hline \multicolumn{9}{|l|}{ Pre Pron } \\
\hline \multicolumn{9}{|l|}{ Imm Pron } \\
\hline \multicolumn{9}{|l|}{ Pre Ortho } \\
\hline \multicolumn{9}{|l|}{ Imm Ortho } \\
\hline \multicolumn{9}{|l|}{ Pre Total } \\
\hline Imm Total & & & & & & & & \\
\hline
\end{tabular}

Legend: Percentage of Confidence Level 90\%

$95 \%$

Consistently, it can be gleaned in the preceding tables, both in the two videos, that the pretest scores across the three skills are generally 0 to 2 only which have increased as shown in the immediate and the delayed posttest scores. Tables 2 and 4 have confirmed that the increase is statistically significant after the video exposures. However. no significant differences were found between the immediate posttest and the delayed posttest scores which means that their acquired literacy skills were mostly retained even days without exposure to the intervention because there was no significant decrease or increase of scores between the two posttests.

\subsection{Extent of Incidental Literacy Skills Acquisition}

The degree to which the pretest, immediate posttest and delayed posttest scores in all literacy skills for both videos are correlated with one another is also a part of this study's investigation. How one literacy skill has correlation within its test results and with other literacy skills are determined through statistical tools and qualitative discussion.

Since in this study, language is seen to be operating as a whole in the context of L2 incidental literacy acquisition, this paper determined the significant interrelationship between the scores within one skill and across the three literacy skills. The following findings support the paper's claims that 
language or literacy acquisition is wholistic - the acquisition of one literacy skill leads to the acquisition of another skill.

As presented in Table 6 that follows, the blue intersections follow a 95\% confidence level. This means that there are high correlations between the vocabulary, pronunciation, and orthography skills.

Table 6. Table of Significant Correlations as Tested Via Kendall Rank Order Correlation Test for Video 1 (nonparametric analog of the Pearson's Test for test of correlation)

\begin{tabular}{llcc}
\hline \multicolumn{1}{c}{ Test } & \multicolumn{1}{c}{ Variable } & Video 1 \\
\hline Immediate Posttest & Vocabulary & $100 \%$ & $83 \%$ \\
\multirow{2}{*}{ Posttest } & Pronunciation & & $83 \%$ \\
& Vocabulary & $89 \%$ & $93 \%$ \\
\hline
\end{tabular}

Table 7. Table of Significant Correlations as Tested Via Kendall Rank Order Correlation Test for Video 2 (nonparametric analog of the Pearson's Test for test of correlation)

\begin{tabular}{llll}
\hline \multicolumn{1}{c}{ Test } & \multicolumn{2}{c}{ Variable } & Video 2 \\
\hline \multirow{3}{*}{ Immediate Posttest } & & Pronunciation & Orthography \\
\multirow{3}{*}{ Posttest } & Vocabulary & $81 \%$ & $89 \%$ \\
& Pronunciation & & $92 \%$ \\
& Vocabulary & $89 \%$ & $79 \%$ \\
& Pronunciation & & $96 \%$ \\
\hline
\end{tabular}

Table 7 above presents the significant correlations of the literacy skills scores in the second video. Consistently, there are also positive interconnections between the vocabulary, pronunciation, and orthography skills outcome results with a $95 \%$ confidence level.

This high correlation of one literacy skill with the other literacy skills implies that when one literacy skill is acquired by the learner, there is a high probability that the learner will also acquire the other literacy skills in the process. The results from the pretest, immediate posttest and delayed posttest are highly correlated, interconnected with each other as well and across the other literacy skills. This justifies the claim that literacy acquisition works holistically. The acquisition of one literacy skill leads to the acquisition of another literacy skill. The vocabulary acquisition primarily also leads to the other literacy skills. This implies that if the learner gave an incorrect vocabulary (failure to recognize a word and its meaning), there is a high probability that the pronunciation and orthographic skills will be incorrect as well (failure to spell and pronounce a word).

One aspect that was also explored is the frequency of the target words presented in the video. It should be noted that target words need to be present in the video in three forms - audio-visual-textual cues. It was found that the target words with the highest frequency (words mentioned many times) in the two videos were acquired by more than half of the pupils across the three skills. We refer to frequency here as the input frequency (Ambridge, Kidd, Rowland \& Theakston, 2015). In contrast, low frequency target words were only acquired by less than half of the learners. Examples are the target words mouse (Video 1) and meat (Video 2) which were the sole words mentioned eight times in each video while the rest of the words were mentioned only once or twice. Results show that four out of six children (Video 1) and five out of six children (Video 2) acquired the words, respectively. This corroborates the findings of Schwartz and Terrel (1983 as cited in Ambridge et. al, 2015).

\subsection{Relationship of Comprehension Skills to the Other Literacy Skills}

Task-induced Involvement after each video exposure facilitated not only the incidental acquisition of comprehension skills but also the incidental acquisition of vocabulary, oral and orthographic skills. The tasks provided a way for the participants to share their ideas and 
understanding of the two stories presented in audio-visual input. Since tasks were presented as play, all of them enthusiastically did the tasks while interacting with the other children when the WH questions were asked as part of the task completion. Typical among children, arguments also arose among them in completing the tasks, but these arguments were tolerated with the aim that these can induce critical thinking and more team discussion allowing them to receive more incidental linguistic input. The participants' comprehension skills were, therefore, incidentally acquired within the process. This was shown when the children were able to recognize the characters of the story, describe their traits, understand, and discuss the story's plot and share the moral lesson of the story.

In answering the basic WH-questions, answers to these questions included the target words that will supply the answer. Hence, to answer the comprehension questions, the children utilized their vocabulary and oral acquisitions to explain events in the story. This became an indicator how tasksinduced involvement facilitates incidental literacy skills acquisition. Consequently, with attentioninducing and effective Task-Induced Involvement and multiple exposures to videos, children will obtain complete incidental acquisitions of the literacy skills.

The result on vocabulary acquisition findings of this study corroborate previous research (e.g. Jensen, 2016); Sylven and Sundqvist, 2012) who both explored the relationship of gaming and the development of English vocabulary knowledge. Their study found that the frequency of the children's exposure to gaming was correlated significantly to their high score on the vocabulary test. Consistently across all literacy skills, the $90 \%$ to $95 \%$ confidence level in the pretest vs. delayed posttest scores indicates that the participants had retained most of the target words from the pretest to the delayed posttest even with an eight-day interval. The results also imply that the longer the students are exposed to a word, there is a strong likelihood that they will retain the meaning associated with the word. The repetition of the words in the video was also significant before the pupils fully acquired them.

In terms of pronunciation (oral vocabulary), the video exposure and the tasks which required them to use the target words in their conversation with their peers contributed to these target words' oral vocabulary skill to be acquired. As presented in the statistical data above, the extent of the literacy skills acquisition reaches to the orthography skills thus proving a complete acquisition from comprehension, vocabulary, pronunciation, and orthography. Though in few cases, some pupils obtained partial acquisitions only, such as correct vocabulary and correct pronunciation with incorrect spellings. However, it is greatly evident in all the data presented that when one literacy skill was acquired, the participants also acquired other literacy skills which led to complete literacy skills acquisitions (ILSA). In a similar way, the incorrect answer to one literacy skill affects the other literacy skills causing partial acquisitions. Llach \& Gomez' (2007) study supported this claim where they found that a child spells a word according to his/her pronunciation. Spelling affected pronunciations, pronunciations affected spellings, incorrect vocabularies affected both spellings and pronunciations. These literacy skills correlated with each other.

Furthermore, the Kendall Rank Order Test proved that the vocabulary posttests scores are correlated or covaried with each other including the pronunciation posttests scores and the orthography posttests scores. The vocabulary, pronunciation and orthographic skills are also found out to be correlated or interrelated to one another based on the scores. In other words, correlations and interconnectedness exist within test scores of one literacy skill and across test scores of other literacy skills. The findings on the high frequency words with more children acquiring them across the three skills corroborates the Dual-Coding Theory by Paivio (2006) which state that these units presented as verbal and non-verbal cues in audio-visual input can function unconsciously to improve cognitive performance (Paivio, 2014 as cited in Kanellopoulou, Kermanidis and Giannakoulopoulos, 2019). The non-verbal and verbal codes occurring frequently may have positive impacts on recall (Kanellopoulou, Kermanidis and Giannakoulopoulos, 2019). This supports Ambridge, Kidd, Rowland \& Theakston (2015) claim that "All other things being equal, frequent forms will be acquired before less-frequent forms" (p.241). Focusing solely on input frequency, Schwartz and Terrel (1983) as cited in Ambridge, Kidd, Rowland \& Theakston (2015) also found that highfrequency words were correctly recalled significantly and consistently than low-frequency words. Hence, for pedagogical implications, language input in both cues is undoubtedly effective and more importantly, if the frequency is increased. 
Lastly, findings of this study contribute to the existing researches that prove the effectiveness of the involvement of tasks that created the levels of need, search and evaluation of meanings (Laufer and Hulstijn, 2001). Thus, the preceding data show that there is a significant effect in the pupils' incidental vocabulary acquisition after the intervention of animated cartoons with closed-captions with the facilitation of Task-Induced Involvement where the extent of comprehension leads to the incidental acquisition of vocabulary, pronunciation, comprehension and orthographic skill. Hence, the null hypothesis is rejected.

\section{Conclusion}

The quantitative and qualitative data in this study proved that there is a significant difference in the children's pretest, immediate posttest and delayed posttests scores after the intervention. Hence, incidental literacy skills acquisition is possible using animated videos with closed-captions and TaskInduced Involvement. The extent of acquisitions is complete and wholistic which begins with the acquisition of comprehension skills followed by vocabulary, pronunciation and orthographic skills. In addition, retention of acquired words after a period of time is possible. Furthermore, literacy skills are significantly correlated to one another. L2 incidental literacy skills acquisition works as an interconnected cycle where the acquisition of one skill leads to the acquisition of another literacy skill. Thus, proving the interconnectedness and relationship of each of the literacy skills. This further provides another view towards L2 literacy learning. Lastly, integrating fun group activities that involve language tasks after video exposures will serve as good motivations of cognitive noticing processes and facilitating incidental acquisition of comprehension skills which lead towards incidental acquisitions of other literacy skills among young learners.

Therefore, animated videos and Task-Induced Involvement can be effective classroom tools for young learners to incidentally acquire second language literacy skills and eventually retain these acquisitions days after the last intervention. The investigation into this occurrence will also be helpful to the curriculum designers and teachers in incorporating digital media to the lessons they teach in the classroom. Hence, the use of TII and animated videos such as PinkFong's Aesop Fables to early grade schoolers is an effective teaching strategy for L2 incidental learning in the Filipino classroom. With the limitations of this study which include a pre-experimental research design and shorter viewing session, the findings of this study can be further explored and confirmed with the utilization of static group comparison. Furthermore, a long-term consumption of audio-visual input with a delayed posttest conducted after a month to further assess retention is suggested to further the findings of this study on the effects of the audio-visual input to the children's incidental literacy skills. Children as recipients of audio-visual input should also be explored more with the limited literature in this area that focus more on teenagers and university students.

\section{References}

Ambridge B., Kidd, E., Rowland, C. \& Theakston, A. (2015). The ubiquity of frequency effects in first language acquisition. Journal of Child Language, 42 (2), 239-273. doi: 10.1017/S030500091400049X

Blanchard, J. \& Moore, T. (2010). The Digital World of Young Children. Impact on Emergent Literacy. Arizona State University.

Craik, F. I., \& Lockhart, R. S. (1972). Levels of processing: A framework for memory research. Journal of Verbal Learning and Verbal Behavior, 11(6), 671684.Retrieved

from http://wixtedlab.ucsd.edu/publications/Psych\%20218/Craik_Lockhart_1972.pdf

Critcher, C., (2008). Making waves: Historical aspects of public debates about children and mass media. In k. Drotner\& S. Livingston (Eds.), International Handbook of Children, Media and Culture. London: Sage.

De Wilde, V. \& Eyckmans, J. (2017). Game on! Young learners' incidental language learning of English prior to instruction [PDF file]. Studies in Second Language and Teaching, 7 (4), 673-694. 
d'Ydewalle, G. \& Van de Poel, M. (1999). Incidental foreign language acquisition by children watching subtitled television programs. Journal of Psycholinguistic Research, 28, 227-244. https://doi.org/10.1023/A:1023202130625

Gunn, B., Simmons, D. \& Kameenui, E. (2004). Emergent literacy: Synthesis of the Research https://www.researchconnections.org/childcare/resources/2776/pdf.

Harun, S., \& Tedlos, C. (2013). Assessing the Effects of Animated Cartoon and TaskInduced Involvement on Preschool Children's L2 Incidental Vocabulary Acquisition (An Undergraduate Thesis). Mindanao State University, Iligan Institute of Technology, Iligan City, Philippines.

Huang, R.Y. (2008). Testing the Involvement Load Hypothesis: Effects of reading-based tasks on vocabulary retention by Chinese FEL learners [PDF file]. Modern Foreign Languages, 27(4), 386-393.

Hulstijn, J. \& Laufer, B. (2001). Some empirical evidence for the involvement load hypothesis in vocabulary acquisition [PDF file]. Language Learning, 51, 539-558.

Kapur, M. (2011). Counselling Children with Psychological Problems. New Delhi, India: Dorling Kindersley.

Jensen, S.H. (2016). Gaming as an English language learning resource among young children in Denmark. CALICO Journal, 34(1). doi: 10.1558/cj.29519

Kanellopoulou, C., Kermanidis, K.L and Giannakoulopoulos, A. (2019). The Dual-coding and Multimedia learning theories: Film subtitles as a vocabulary teaching tool. Education Sciences, 9(3). doi.org/10.3390/educsci9030210

Timothy S. \& Christopher J. L. (2017). The Role of Early Oral Language in Literacy Development. Retrieved from https://www.languagemagazine.com/5100-2/.

Laufer, B. \& Hulstijn, J.H. (2001). Incidental vocabulary acquisition in a second language: The construct of task-induced involvement. Applied Linguistics, 22(1), 1-26. https://doi.org/10.1093/applin/22.1.1

Lin, L. (2010). English learners' incidental vocabulary acquisition in the video-based CALL program [PDF file]. Asian EFL Journal. 12 (4). https://www.asian-efljournal.com/PDF/Volume-12-Issue-4-Lin.pdf

Liu, C. (2015). A review of effect of different tasks on incidental vocabulary acquisition. Higher Education Studies, 5(5), 56-63. doi:10.5539/hes.v5n5p56

Llach, P. \& Gomez, A. (2007). Children's Characteristics in Vocabulary Acquisition Use in the Written Production. RELSA (20), 9-26.

Mielonen, A.M. \& Paterson, W. (2009). Developing literacy through play [PDF file]. Journal of Inquiry and Action in Education, 3 (1).

Paivio, A. (2006). Dual Coding Theory and Education [PDF file]. Retrieved from http://coral.ufsm.br/tielletcab/Apostilas/DCT_Paivio.pdfLanguage: 22/1, 26.

Perez, M.M. \& Rodgers, Michael P. H. (2019). Video and language learning (Guest Editorial). The Language Learning Journal. 47:4, 403-406, DOI: 10.1080/09571736.2019.1629099.

Ponniah, R. (2011). Incidental acquisition of vocabulary by reading [PDF file]. An International online journal, 11(2), 135-139. Retrieved from http://www.readingmatrix.com/articles/april_2011/ponniah.pdf

Terry, S. (2020). Reading and Literacy. Retrieved from https://www.air.org/topic/reading-andliteracy

Rideout, V., Hamel, E., \& Kaiser Family Foundation. (2006). The media family: Electronic media in the lives of infants, toddlers, preschoolers and their parents [PDF file]. Menlo Park, CA: Kaiser Family Foundation.

Savielle-Troike, M. (2012). Introducing second language acquisition (2 $2^{\text {nd }}$ ed.). Cambridge: Cambridge University Press. 
Sundqvist, P. (2019). Commercial-off-the-shelf games in the digital wild and L2 learner vocabulary. Language Learning \& Technology, 23(1),87-113. https://doi.org/10125/44674.

Vulchanova, M., Baggio, G., Cangelosi, A. \& Smith, L. (2017). Editorial:Language development in the digital age. Frontiers in Human Neuroscience. https://doi.org/10.3389/fnhum.2017.00447

Whitehurst, G. \& Lonigan, C. (1998). Child development and emergent literacy [PDF file]. Child Development, Volume 69 (3). https://doi.org/10.1111/j.14678624.1998.tb06247.x

Xiaoning, C. \& Feng, T. (2017). Assessing the effects of word exposure frequency on incidental vocabulary acquisition from reading and listening. Chinese Journal of Applied Linguistics, 40(1) https://doi.org/10.1515/cjal-2017-0004

Zeeland, H.V. \& Schmitt, N. (2013). Incidental vocabulary acquisition through L2 listening: A dimensions approach. https://doi.org/10.1016/j.system.2013.07.012

Zhao, A., Guo, Y., Biales, C. \& Olszewki, A. (2016). Exploring learner factors in second language (L2) incidental vocabulary acquisition through reading [PDF file]. Reading in a Foreign Language, 28 (2), 224-245. Retrieved from https://pdfs.semanticscholar.org/5db0/ae9e65a498542b6fb03dd6fc92ff36d2ae4a.pdf 